\title{
Evaluation on the Application of Quality Management System in Tanzania Building Construction Projects
}

\author{
Japhary Juma Shengeza \\ Built Environment Engineering (BEE), College of Engineering and Technology, Mbeya University of Science and Technology, Mbeya, \\ Tanzania
}

Email address:
shengeza@yahoo.com

To cite this article:

Japhary Juma Shengeza. Evaluation on the Application of Quality Management System in Tanzania Building Construction Projects. American Journal of Management Science and Engineering. Vol. 2, No. 6, 2017, pp. 170-175. doi: 10.11648/j.ajmse.20170206.12

Received: February 17, 2017; Accepted: March 31, 2017; Published: October 31, 2017

\begin{abstract}
In today's construction projects, client satisfaction demand require the building team in construction industry to achieve high quality during construction process. This excellence can be achieved with a new style of management of a system that guides the interaction of people, processes and documentation which is referred to as Quality Management System (QMS). The study has evaluated the application of Project Quality Plan (PQP) as one of the implementation strategies of QMS in construction projects. The data was collected by use of questionnaire; interview and document review. Primary data from 32 medium and large scale high rise building construction projects located in Dar es Salaam city were sampled through nonprobability sampling. The findings have established that PQP preparation and application in construction building project is done at low key. PQP application only limited to inspection and test plans. Amongst the contributing factors to the low level of PQP application are: frequent revision and change order by the owner, design changes by supervising consultants and lack of knowledge on QMS as a strategic weapon to achieve quality in construction industry. It is therefore recommended that the Tanzania government through construction governing bodies has to play an important and positive role to train on the application of PQP through workshops and seminars to members of the construction building team. It is further recommended that to enhance the application of QMS and facilitate quality services in construction projects, a provisional clause be introduced in conditions of contract.
\end{abstract}

Keywords: Quality Management System (QMS), Project Quality Plan (PQP), Construction Projects

\section{Introduction}

Construction is one of the major human activities that provide man with basic infrastructure, shelter and other facilities necessary for economic and social development. It provides the economic infrastructure, which is required to attract foreign direct investment, and enhance national competitiveness. Also, it helps to distribute wealth in the societies through work opportunities, such as labourintensive methods and commercial potentials for small and medium-sized business enterprises [1].

Construction projects involve many participants including the owner/client, designer, contractor, and many other professionals from construction-related industries. Each of these participants is involved in implementing quality in construction projects. These participants are both influenced by and depend on each other in addition to "other players" involved in the construction process. Furthermore, the construction projects have become more complex and technical, and extensive efforts are required to reduce rework and costs associated with time, materials and supervisions [2].

Quality has become the most important single factor for the survival and success of today's companies. Customers demand for better products and services at the lowest possible costs, which in turn, has exerted tremendous pressure on firms to improve the quality of products, services, and processes to compete in the market and improve business results. It became important that construction projects be more qualitative, competitive and economical to meet owner's expectations. According to [2] construction project quality is the fulfilment of the owner's needs per defined scope of works within a budget and specified schedule to satisfy the owner's/user's requirements. All firms 
have management procedures and instructions for creating and delivering their products to customers.

[3], the vocabulary of quality defined quality management as "all activities of the overall management function that determine the quality policy, objectives and responsibilities, and implement them by means such as quality planning, quality control, quality assurance and quality improvement, within the quality system". Meanwhile, the definition of quality system according to [3] is "the organizational structure, responsibilities, procedures and resources needed to implement quality management". Combining the definitions of 'quality system' and 'quality management', it is thus concluded that quality management system (QMS) is the interaction of people, processes and documentation to meet both customers' stated and implied needs [4]. [5] define quality management system as an internal quality system which covers activities aimed at providing confidence to the management of an organization intended to ensure that quality is achieved. Business dictionary defined QMS as a system by which an organization aims at reducing and eventually eliminating non-conformance to specifications, standards and customer expectations in the most cost effective and efficient manner.

It is believed that if the objectives of a firm are well defined and appreciated by all employees, the responsibilities of the department and the designation are clearly delineated and the procedures are well documented, it is likely that the products or services of the firm are "fit for purpose" and meeting the clients' requirements. This is important as for a company to remain viable it should meet the two essential factors, that is, to satisfy the client and to make profit [4]

QMS has been particularly widely adopted by the construction industry through its model of International Standards on Quality Management and Quality Assurance (ISO 9000) [6, 7, 8, 9, and 10]. The pressure also comes from the on-going process of economic globalization. Experiences learned from other countries in the introduction of QMS such as United Kingdom, Singapore and Hong Kong revealed that QMS implementation was very encouraging at the initial stage but over a time period became burdensome to all parties involved when the right approaches were not adopted [11]. In the United Kingdom, some of the construction industry clients made it compulsory that the contractors implement ISO quality system in their organizations to qualify for participating in the bids [12]. Total quality management (TQM) and the latest version of ISO 9000 that is Quality Management System -Fundamentals and Vocabulary (ISO 9000:2000) are example models of QMS [5].

According to [11], there are several studies which have been conducted on QMS that focused on implementation of ISO 9000 QMS in construction organization on applicability, benefits and obstacles of implementing it within each country such as USA, Singapore, Hong Kong, UK, Taiwan, Saudi Arabia and Malaysia. However, as construction is a projectbased industry, the success of QMS implementation should not be measured at the company level only but its benefits should be extended to the project level.

Few studies have been conducted on implementation of QMS at project level. For example, a study was conducted in Malaysia on the capability of a construction project team in the implementation of a quality management system by indicating the need for project quality plan both for supervisory consultants and contractors [5].

In a developing country like Tanzania where the construction sector is most vibrant sector in the economy [13], the consideration of QMS in construction industry seems necessary.

\section{Statement of the Problem}

In recent years in Tanzania, construction of high rise buildings in the major cities has increased. According to [13], between 1996 and 2006 a total of 1,000 high rise buildings were under construction in Dar es Salaam city. Problems of poor quality within building construction projects have been manifested with collapse of some of high rise buildings, unsafe structure, disputes and cost of delay, reworking and rejects. Every building construction projects need to be completed with high quality and achieve customer satisfaction. It is from this background that QMS is seen as a solution for improving the quality of projects within the construction industry. It is a strategic weapon that enhances commitments to address quality standards and regulatory requirements [14].

As the Tanzania construction industry is now promising to become the engine of national economic development, achieving of quality and higher performance not only domestically but also in the international market [13] is paramount. The question is to what extent QMS as a management tool to address quality standards and regulatory requirements has been applied within Tanzania building construction project? This study intends to evaluate the existence of project quality plan in building construction projects as a quality management system strategy.

\section{Research Approach and Methodology}

The study of the thirty two construction projects of medium and large scale of high rise building construction projects of more than five floors but less than ten floors and ten floors and above respectively at post contract stage of construction process provided a population with required diversity, representation, accessibility and knowledge. The sample of high rise building construction projects at post contract stage suited the objective of this study, saved time, reduced complexity and eliminated the effects of sampling biasness and errors. The instruments used included questionnaires, interviews and documents review. Strategically, the study employed both quantitative and qualitative techniques.

Profile of Respondents and Questionnaire Responses

The data collection process by this method was quite good. Out of 32 distributed copies of the questionnaire, 26 copies - 
which is equivalent to 81.25 percent of the respondents, were returned. Table 1 below summarizes the data collection process by comparing distributed and returned questionnaire responses.

Table 1. Distributed and attained Questionnaire responses.

\begin{tabular}{llll}
\hline Respondents from & Number of Questionnaire & & Returned \\
\hline & Distributed & 12 & Percentage of Success \\
\hline Medium scale high rise construction projects & 17 & 14 & $70.59 \%$ \\
Large scale high rise construction projects & 15 & 26 & $93.33 \%$ \\
Total & 32 & $81.25 \%$ & \\
\hline
\end{tabular}

\section{Data Analysis and Findings}

\subsection{Evaluation of Existence of Preparation and Application of PQP in Previous Building Construction Projects}

A question was designed to allow respondents to give information on using PQP in building construction projects in previous undertaken high rise building construction projects in order to help the researcher make comparison later on regarding the application of PQP between previous and current high rise building construction projects. The information required was to give the most common, common and not common constituents of PQP prepared and applied during post contract stage in previous construction projects as detailed scope of the project, quality plan inputs, quality objectives, purchasing plan, management responsibilities, control of documents and data, design control plan, resources needed plan, inspection and test plan, audits plan, production and service provision, control of data plan, preservation of product plan and control of nonconforming plan, making the total of 14 constituents of PQP. 46 percent of respondents showed that constituents of PQP were most commonly prepared and applied. 35 percent of respondents showed that constituents of PQP were commonly prepared and applied while 18 percent of respondents showed that constituents of PQP were not commonly prepared and applied in previous building construction projects. 92 percent of respondents showed that inspection and test plans were most common constituents of PQP prepared and applied. 8 percent said that they were commonly prepared and applied while no respondent indicated that inspection and test plan were commonly prepared and applied during post contact stage in previous building construction projects. The responses are summarized in Table 2.

From the results given in Table 2 some of the constituents of PQP were not most common prepared and applied. This was due to lack of awareness on the importance of these constituents of PQP as a means to control quality achievement in building construction projects and the meaning of quality in building construction projects. The reason for inspection and test plan being chosen as the most common used method was due to traditional methods of controlling quality during post contract stage. To achieve quality in construction projects, other constituents of PQP should not be ignore.

Table 2. Evaluation of Existence of Preparation and Application of PQP in Previous Building Construction Projects.

\begin{tabular}{|c|c|c|c|}
\hline \multirow[t]{2}{*}{ Constituents of PQP } & \multicolumn{3}{|c|}{ Percentage of Respondents } \\
\hline & Most common & Common & Not common \\
\hline Detailed scope of the project & $54 \%$ & $46 \%$ & $0 \%$ \\
\hline Quality plan inputs & $46 \%$ & $38 \%$ & $15 \%$ \\
\hline Quality objectives & $42 \%$ & $58 \%$ & $0 \%$ \\
\hline Purchasing plan & $54 \%$ & $23 \%$ & $23 \%$ \\
\hline Management responsibilities & $42 \%$ & $58 \%$ & $0 \%$ \\
\hline Control of documents and data & $69 \%$ & $19 \%$ & $12 \%$ \\
\hline Resources needed plan & $58 \%$ & $23 \%$ & $19 \%$ \\
\hline Inspection and test plan & $92 \%$ & $8 \%$ & $0 \%$ \\
\hline Audits plan & $0 \%$ & $65 \%$ & $35 \%$ \\
\hline Production and service provision & $46 \%$ & $31 \%$ & $23 \%$ \\
\hline Control of data plan & $35 \%$ & $35 \%$ & $31 \%$ \\
\hline Preservation of product plan & $35 \%$ & $31 \%$ & $35 \%$ \\
\hline Control of nonconforming product plan & $0 \%$ & $35 \%$ & $65 \%$ \\
\hline
\end{tabular}

(Where the percentage of respondents range from $0 \%-49 \%=$ inadequate, $50 \%-79 \%=$ good, $80 \%-100 \%=$ excellent)

\subsection{Dominant Obstacles Against the Application of PQP in High Rise Building Construction Projects}

Respondents were required to respond on the dominant obstacles against the application of PQP in high rise building construction projects by ranking them according to their criticalness i.e. 5 representing very critical and 1 less representing critical. The dominant obstacles listed down for respondents were: frequent revision and change order by the owner, lack of cooperation from the owner, ineffective cooperation between contractors and designers, frequent design changes by supervising consultant, lack of knowledge 
of quality management systems, lack of skills and knowledge in the preparation and application of inspection and test plan, poor communication among professionals during implementation of project, poor availability of equipment for inspection and testing, poor communication among contractors, obeying traditional methods of construction without agreeing on new changes and ineffective supervision of governments boards to meet required standards. From the responses, ranking mean scores were obtained and it was easy to rank the results accordingly by comparing the mean scores as shown in Table 3.

Table 3. Dominant Obstacles against the Application of PQP in High Rise Building Construction Projects.

\begin{tabular}{|c|c|c|c|}
\hline Project Quality Plan Obstacles & Scores & Mean Scores & Rank \\
\hline Frequent revision and change order by the owner & 126 & 4.85 & 7 \\
\hline Lack of cooperation from the owner & 115 & 4.42 & 2 \\
\hline Ineffective cooperation between contractors and designers & 121 & 4.65 & 6 \\
\hline Frequent design changes by supervising consultant & 126 & 4.85 & 7 \\
\hline Lack of knowledge of quality management systems & 126 & 4.85 & 7 \\
\hline Lack of skills and knowledge on preparation and application of inspection and test plan & 119 & 4.58 & 4 \\
\hline Poor communication among professionals during implementation of project & 121 & 4.65 & 6 \\
\hline Poor communication among contractors & 116 & 4.46 & 3 \\
\hline Obeying traditional methods of construction without agreeing on new changes & 120 & 4.62 & 5 \\
\hline Ineffective supervision of governments boards for meeting required standards & 120 & 4.62 & 5 \\
\hline
\end{tabular}

The results show that frequent revision and change order by the owner, frequent design changes by supervising consultant and lack of knowledge of quality management systems are very critical dominant obstacles against the application of PQP with mean scores of 4.85 , followed by ineffective cooperation between contractors and designers as well as poor communication among professionals during implementation of project with mean scores of 4.65. Obeying traditional methods of construction without agree on new changes and ineffective supervision of government boards for meeting required standards were ranked third with mean score of 4.62. Lack of skills and knowledge in preparation and application of inspection and test plan was ranked the fourth with 4.58 mean score. Poor communication among contractors was the fifth with 4.46 mean score and lack of cooperation from the owner was the seventh with 4.42 mean score. The less critical dominant obstacle was poor availability of equipment for inspection and testing with mean score of 4.38 .

\subsection{Measures to Enhance the Application of QMS in Construction of High Rise Building Projects}

Respondents were required to suggest measures to be adopted in order to improve the application of QMS in construction of high rise building projects in Tanzania. The question asked was "What do you think should be done in order for Tanzania to improve the application of quality management system in construction of high rise building projects?" The following are the measures suggested:

\subsubsection{Establishment of Special Boards}

Establishment of special boards which will be responsible for all matters concerning QMS in construction industry which will work together with other regulatory boards in construction industry like CRB, ERB and AQRB.

\subsubsection{Training on Issues Concerning QMS}

Regular training on issues concerning QMS in construction industry to all building team members.

\subsubsection{Regulatory Boards to Enforce QMS}

Laws/regulations should allow regulatory boards (CRB, ERB and AQRB) to enforce QMS. For example, the necessary documents as per requirements of QMS in construction industry should be submitted to the concerned regulatory boards before the firm is registered to perform certain activities in construction industry.

\subsection{Evaluation of the Implementation of PQP in Current Building Construction Projects}

A question was designed to evaluate the constituents of PQP which were prepared during post contract stage in the sampled building construction projects as means to address quality achievement in current projects. Table 4 shows the responses.

Table 4. Evaluation of the Implementation of $P Q P$ in Current Building Construction Projects.

\begin{tabular}{ll}
\hline Constituents of PQP & Percentage of respondents \\
\hline Detailed scope of the project & $69 \%$ \\
Quality plan inputs & $54 \%$ \\
Quality objectives & $46 \%$ \\
Purchasing plan & $46 \%$ \\
Management responsibilities & $58 \%$ \\
Control of documents and data & $42 \%$ \\
Design control plan & $69 \%$ \\
Resources needed plan & $35 \%$ \\
Inspection and test plan & $77 \%$ \\
Audits plan & $35 \%$ \\
Production and service provision & $42 \%$ \\
Control of data plan & $42 \%$ \\
Preservation of product plan & $12 \%$ \\
Control of nonconforming product plan & $12 \%$ \\
Total average percentage & $46 \%$ \\
\hline
\end{tabular}

(Where the percentage of respondents range from $0 \%-49 \%=$ inadequate, $50 \%-79 \%=$ good and $80 \%-100 \%=$ excellent)

From the data in the Table 4, it is shown that 77 percent of responses showed that the inspection and test plan were 
prepared in the sampled building construction projects at post contract, 12 percentonly of responses showed that preservation of product plan and control of nonconforming product plan were prepared during post contract stage in high rise building projects. On the other hand, 46 percent of the respondents as an average for all 14 constituents of PQP showed that constituents of PQP were prepared during post contract stage in the sampled construction of high rise building construction projects.

From the above findings and interpretation, it is clear that inspection and test plan is considered to be more prepared in the sampled construction projects as a means to control quality as compared to other constituents of PQP. This was due to the fact that inspection and test plan is one of the traditional methods used to control quality achievement in construction projects. In contrast, preservation of product plan and control of nonconforming product plan have less prepared as constituents of PQP in the sampled construction of high rise building projects. This was because of lack of awareness of technical staff on the importance of the constituents of PQP to address commitment on achievement of quality during post contract stage.

\section{Conclusion and Recommendations}

\subsection{Conclusion}

This study has evaluated the implementation of PQP as a component of QMS in construction of high rise building construction projects. The study also evaluated the existence of application of constituents of PQP and identified dominant obstacles in application of PQP for building construction projects. The following are the conclusions drawn from study:-

\subsubsection{Existence of PQP in Building Construction Projects In Tanzania}

The findings indicate that the existence of constituents of PQP as a means to address quality in building construction project is inadequate for construction of high rise building projects under study. However, most common constituents practice in building construction projects is inspection and test plan. Basically, this is due to traditional of controlling quality of the construction projects. The contribution of inspections and test plans to quality is merely partial while quality in building construction is considered to be the fulfilment of the owner's needs per defined scope of works within a budget and specified schedule to satisfy the owner's/user's requirements. In this concept, other constituents of PQP should be considers as well.

\subsubsection{Implementation of PQP as $A$ Component of $Q M S$ in Tanzania Construction Projects}

The findings indicate implementation of PQP in building construction projects is unsatisfactory. It has been observed that no formal procedures are used as means to control quality. Dominant documents used formally are the schedule of materials which determine the quantities of materials to be purchased and the use of site meeting minutes and programme of works which help to monitor the progress of works not how to achieve quality. Implementation of PQP as a component of QMS is unsatisfactory as there are no formal procedures for quality processes.

\subsubsection{Dominant Obstacles Against the Application of PQP in Building Construction Projects in Tanzania}

Most respondents commented that frequent revision and change order by the owner, frequent design changes by supervising consultant and lack of knowledge of quality management system are first ranked as very critical dominant obstacles for preparation and application of PQP. Ineffective cooperation between contractors and designers due to lack of team work spirit among members of building was second ranked by respondents as a very critical dominant obstacle in the preparation and application of PQP in Tanzania construction projects.

\subsection{Recommendations}

\subsubsection{Training for the Application of PQP in Building Construction Projects in Tanzania}

In order to enhance the application of PQP in construction industry, efforts should be made to have regular training regarding the application of $\mathrm{PQP}$ as one of the component of QMS through workshops and seminars to members of the construction building team (Contractors, Architects, Engineers, Quantity surveyors, Suppliers and Technicians) by National Construction Council (NCC). This should be done through regulatory boards and associations in construction industry on the effective application of QMS in construction industry as a weapon to address quality achievement in construction projects. The researcher also proposes the introduction of QMS in teaching programmes such as National Technical Award (NTA) courses of engineering and construction awarded through vocational training centres and universities.

\subsubsection{Reinforcing Contractual Provisions to Improve the Implementation of PQP}

It is highly recommended that a clause that supports the application of QMS should be introduced in the conditions of contracts. In advanced countries, the introduction of QMS incentive clauses like requirements for all contractors who are participating in the bids to be registered with ISO 9000 and practice QMS into conditions of contracts has made changes in the application of QMS in construction industry [12]. If such a clause is introduced in developing countries like Tanzania, it will encourage the building team to practice QMS in construction industry which will help to improve formal application of PQP in Tanzania construction projects.

\subsubsection{Team Work Spirit in Building Construction Projects}

It is important for all actors in building construction projects to work as a team from the inception of the project to the end of the project. At present this is the practice. On registering a project with any of the Boards the other team members have to appear. Also, actors in building 
construction projects should accept team working and sharing of ideas in order to overcome problem of frequent revision and change order by the owner and frequent design changes by supervising consultants. Through this, the application of PQP will increase resulting into more achievement of quality during construction project.

\section{References}

[1] ILO, "Report on Construction Sector in Twenty First Century", Retrieved: http//www.oit/org. October 9, 2016.

[2] Rumane, A. R., "Quality Management in Construction Projects" CRC Press Taylor and Francis Group, London, 2011.

[3] ISO 8402: 1994, "Quality Management and Quality Assurance -Vocabulary", Retrieved: from https://law.resource.org. August 20, 2016.

[4] Abdulaziz, A. B and Tawfiq, H. A., "ISO 9000 Quality Standards in Construction", Journal of Management in Engineering, 1999, Nov/Dec: pp. 41-45.

[5] Mohammed, AH. Baba, M. andAbdullah, MN., "An Overview of Quality Management System in Construction”, University Technology Malaysia (UTM), 2008, pp 1-13, Retrieved: January 20, 2017, from http//eprints.utm.my.

[6] Willar, D., "Improving Quality Management System Implementation in Indonesian Construction Companies", $\mathrm{PhD}$ Thesis, Queensland University of Technology, 2012,
Retrieved: January 18, 2017, from http://eprints.qut.edu.au/59202.

[7] Chini, A. R and Valdez, H. E., "ISO 9000 and the US Construction Industry", Journal of Management in Engineering, ASCE 19 (2), 2003, pp. 69-77.

[8] Turk, A. M., "ISO 9000 in Construction: An Examination on its Application in Turkey”, Building and Environment 41 (4), 2006, pp. 501-511.

[9] Lordsleem, A. J, Duarte, C., and Barkokébas, B. J. "Performance Indicators of the Companies Quality Management Systems with ISO 9001 Certification" in CIB 2010 World Congress, 10 -13 May 2010, edited by P. Barrett, D. Amaratunga, R. Haigh and K. Keraminiyage, Salford Quays - United Kingdom, 2010.

[10] Watson, P. and Howarth, T., "Construction Quality Management”, New York: Spon Press, 2011.

[11] Mohammed, A. K and Abdullah, M. N., "Quality Management System in Construction", ICCI-2006, 81310 Johor Bahru Johor, Universiti Teknologi Malaysia. Retrieved: January 27, 2017, from http//eprints.utm.my.

[12] Giles, R., "ISO 9000 Perspective for Construction Industry in the UK”, Training for Quality, Vol. 5, 4, 1997, pp. 178-181.

[13] NCC., "Construction Activities in Tanzania Booming Despite Impeding Challenges, Construction Business", ISSN 08566232, Vol. 12. No. 3/4, edited by John, H. and Fundi, Y., January 2013, p. 3.

[14] Roderick, D., "Quality Management System", Westinghouse Non-Proprietary Class 3, Electrical Company LLC, 2013. 